\title{
Minimum inhibitory concentrations of Staphylococcus aureus recovered from clinical and subclinical cases of bovine mastitis
}

\author{
L. Oliveira, ${ }^{*}$ H. Langoni, $†$ C. Hulland, ${ }^{*}$ and P. L. Ruegg ${ }^{\star 1}$ \\ *Department of Dairy Science, University of Wisconsin, Madison 53706 \\ †Faculdade de Medicina Veterinária e Zootecnia, UNESP, Botucatu-SP 18618-970, Brazil
}

\begin{abstract}
Antimicrobials are often used for treatment of bovine mastitis and the possibility of selection for resistant bacteria must be considered. The objectives of this study were to determine the minimum inhibitory concentration of Staphylococcus aureus recovered from cases of clinical and subclinical bovine mastitis, and to determine the prevalence of multidrug resistance in this population. Milk samples were collected from cows on commercial dairy herds $(\mathrm{n}=13)$, including quarters ( $\mathrm{n}$ $=1,574$ ) of cows with subclinical mastitis cases, and cows experiencing clinical mastitis cases $(\mathrm{n}=608)$. Selected Staph. aureus isolates, obtained from clinical $(\mathrm{n}=58)$ and subclinical $(\mathrm{n}=58)$ mastitis cases, were used to determine minimum inhibitory concentrations of 12 selected antimicrobials. Of Staph. aureus isolates tested, $87(75 \%)$ did not exhibit resistance to any antimicrobial, $28(24.1 \%)$ exhibited resistance to $1(\mathrm{n}=$ $21)$ or $2(\mathrm{n}=7)$ classes of antimicrobials, and $1(0.9 \%)$ exhibited multidrug resistance. All Staph. aureus (clinical and subclinical cases) were inhibited by the range of concentrations tested for ceftiofur and oxacillin. Moreover, no isolates obtained from clinical mastitis cases exhibited resistance to cephalothin, penicillin-novobiocin, or sulfadimethoxine. Of isolates, 3 exhibited resistance to enrofloxacin. Of isolates exhibiting resistance to more than 1 antimicrobial, independent of antimicrobial class, the combination of erythromycin and tetracycline, and ampicillin and penicillin accounted for the majority of resistance. Of isolates tested, $19 \%$ were resistant to tetracycline and $14 \%$ were resistant to penicillin. Survival curves of Staph. aureus relative to minimum inhibitory concentration demonstrated heterogeneity among case types for ceftiofur, cephalothin, and erythromycin. Multidrug resistance was identified in only 1 isolate obtained from a single farm.
\end{abstract}

Key words: Staphylococcus aureus, mastitis, antimicrobial resistance, minimum inhibitory concentration

Received September 15, 2011.

Accepted October 9, 2011.

${ }^{1}$ Corresponding author: plruegg@wisc.edu

\section{INTRODUCTION}

Mastitis is the most prevalent disease of dairy cows and remains as one of the most common reasons to remove cows from production (Pol and Ruegg, 2007). The majority of bovine IMI are caused by Staphylococcus spp., Streptococcus spp., and gram-negative pathogens (Makovec and Ruegg, 2003a). Clinical mastitis is characterized by abnormalities in milk. Subclinical mastitis is characterized by normal appearance of milk with increased numbers of somatic cells. Bovine mastitis caused by Staph. aureus can result in both clinical and subclinical disease (Wilson et al., 1997). Staphylococcus aureus may also cause human infections and is associated with both community acquired and nosocomial morbidity and mortality (Zadoks et al., 2000). Furthermore, methicillin-resistant Staphylococcus aureus is a major cause of hospital-acquired infections of humans and is an important human health problem (Enright et al., 2002).

Mastitis occurs when bacteria are able to successfully infect the mammary gland. After developing mastitis, the probability of a successful cure depends on the immune system of the cow, virulence characteristics of the pathogen, and the efficacy of the treatment protocol. The development of antimicrobial resistance in mastitis pathogens is one factor that reduces the probability of cure. The reported prevalence of penicillin-resistance in Staph. aureus isolated from milk samples obtained from cows in the United States has ranged from 30\% (Makovec and Ruegg, 2003b) to more than 70\% (De Oliveira et al., 2000). Makovec and Ruegg (2003b) analyzed antimicrobial resistance patterns of mastitis pathogens over a 7-yr period and reported an increase in the proportion of Staph. aureus that was resistant to erythromycin and lincomycin, but a decrease in the proportion resistant to penicillin.

Bacteria may be intrinsically resistant to a specific class of antimicrobial due a lack of binding sites or other pharmacological characteristics, or bacteria may acquire resistance to antimicrobials either by mutations in their chromosomal genes or by exchange of genetic material via plasmids or transposons (Neu, 1992). 
Achieving a cure for a mastitis case is highly dependent on host immunity and specific characteristics of the infective organism; thus, antimicrobial susceptibility tests are not always effective in predicting clinical outcomes (Hoe and Ruegg, 2005; Apparao et al., 2009a). However, determination of antimicrobial sensitivity of mastitis pathogens is an important tool for monitoring the development of antimicrobial resistance (Pol and Ruegg, 2007). Previous studies (Hoe and Ruegg, 2005; Pol and Ruegg, 2007) typically used commercially available test panels that have a fixed and standardized range of antimicrobial concentrations to determine minimum inhibitory concentration. The limited range of concentrations is a weakness of those panels because many isolates are inhibited at the lowest concentration or isolates are not inhibited by the test range. Only a few studies have reported research using a wider range of antimicrobial concentrations (Apparao et al., 2009b).

The intense use of antimicrobials can contribute to selection within populations for multidrug-resistant (MDR) pathogens (Barbosa and Levy, 2000). Multidrug-resistant pathogens are defined as resistant to 3 or more classes of antimicrobials (Tenover, 2006; Schwarz et al., 2010). Monitoring the development of MDR pathogens is important because resistant bacterial infections decrease therapeutic options, increase the cost of health care, and can contribute to increased morbidity and mortality (Levy, 1992). Another possible consequence of the development of MDR pathogens in agriculture is the possible transference of MDR genes to human microflora (Burgos et al., 2005).

Understanding the epidemiology of antimicrobial resistance in mastitis pathogens may allow for the development of preventive strategies to decrease existing resistance and to avoid emergence of new strains of resistant bacteria (Guillemot, 1999). The objective of this study was to determine the prevalence of antimicrobial resistance of selected antimicrobials and the MIC distributions among Staph. aureus recovered from cases of subclinical and clinical bovine mastitis using an extended dilution antimicrobial susceptibility assay.

\section{MATERIALS AND METHODS}

\section{Herd, Cow Selection, and Collection of Milk Samples}

Wisconsin dairy herds $(\mathrm{n}=13)$ were recruited through practicing veterinarians and extension agents. Enrollment criteria required herds to have a history of mastitis caused by Staph. aureus. The history was based on the microbiological results of previous bulk tank or individual cow milk cultures. For subclinical mastitis cases, study personnel collected milk samples from eligible cows during a single visit to each farm. Approximately $30 \%$ of milk samples were obtained from cows with apparently new subclinical cases (SCC $>200,000$ cells $/ \mathrm{mL}$ only in the current month of collection), and $70 \%$ were collected from apparent chronic cases ( $\mathrm{SCC}>200,000$ cells $/ \mathrm{mL}$ for 2 or more consecutive months before the visit). For clinical mastitis cases, trained farm personnel collected duplicate quarter milk samples from cows identified with mastitis during a period of 3 to 9 mo following the visit. Clinical mastitis was defined as abnormal milk with or without changes in the udder and included some animals with systemic symptoms.

Milk samples obtained from subclinical cases were cooled rapidly, transported to the University of Wisconsin-Madison's Milk Quality Laboratory, and plated onto bacterial culture media on the same day as it was collected. Somatic cell count was determined by flow cytometry at a commercial DHIA laboratory [AgSource Cooperative Resources International (CRI), Verona, WI]. For clinical cases, farms were supplied with sampling and mailing kits and instructed to freeze samples after collection and then mail them to the laboratory.

\section{Bacteriological Culture}

For the primary culture, $0.10 \mathrm{~mL}$ of each milk sample was streaked on one half of a blood agar plate and one quarter of a MacConkey agar plate. Plates were incubated at $37^{\circ} \mathrm{C}$ for $24 \mathrm{~h}$. Except for an increased inoculum volume, pathogens were identified to the species level using laboratory procedures as defined by the National Mastitis Council guidelines (NMC, 1999). The increased inoculum volume was used to enhance recovery of potentially low-shedding Staph. aureus. Furthermore, to improve recovery of Staph. aureus, Petrifilm Staph Express plates (3M, St. Paul, MN) were used as an enhancement method for some samples that were initially culture negative. Briefly, if no microbial colonies were present in the primary culture (after 24 $\mathrm{h}$ of incubation) the same refrigerated milk samples were incubated for $6 \mathrm{~h}$ at $37^{\circ} \mathrm{C}$, followed by the plating of $1 \mathrm{~mL}$ of milk on a Petrifilm Staph Express plate (3M). Using this system, Staph. aureus was initially identified following the manufacturer's instructions. Staphylococcus aureus was then confirmed by replating 2 representative colonies on blood agar and differentiated from other staphylococci by means of a mannitol and coagulase tube test. Final confirmation was based on API Staph (bioMérieux-Vitek Inc., Hazelwood, MO). Suspected Streptococcus spp. were identified as gram-positive cocci, negative catalase reaction by the Christie, Atkins, Munch-Petersen (CAMP) test, and 
esculin reaction. Gram-negative bacteria were identified using MacConkey agar, motility, indole, and ornithine reactions and growth on triple sugar iron. In addition, identification of most aerobic gram-positive bacteria was determined using the appropriate API system (bioMérieux-Vitek Inc.) with a confidence level greater than $70 \%$. All isolates were frozen and stored until used for further analysis. Milk samples were considered contaminated if 3 or more dissimilar colony types were found in the same sample. Except for Staph. aureus, cultures were considered negative when $<3 \mathrm{cfu}$ of the same colony type were seen on the plate. To increase the sensitivity of recovering Staph. aureus, the presence of $\geq 1$ cfu was considered a positive sample. This alternative detection limit was chosen to minimize false-negative results due to intermittent shedding of Staph. aureus. A quarter was considered infected when the same mastitis pathogen was isolated from duplicate milk samples.

\section{Antimicrobial Susceptibility Testing}

Antimicrobial susceptibility was evaluated for selected Staph. aureus isolated from clinical $(\mathrm{n}=58)$ and subclinical mastitis $(\mathrm{n}=58)$ cases. One cow had 2 samples included in this project, 1 for the clinical case and the other for the subclinical case; all other animals contributed only 1 isolate. For isolates obtained from subclinical mastitis cases, the selected isolates represented a variety of farms, and met specific identification requirements, such as growth in pure culture using blood agar, positive mannitol and coagulase reactions, and $\geq 70 \%$ confidence level reported using API Staph (bioMérieux-Vitek Inc.). For isolates obtained from clinical mastitis cases, susceptibility tests were performed for the first 58 eligible isolates submitted to the laboratory. Ten of 13 farms submitted samples from clinical mastitis cases. Antimicrobial susceptibility was determined using a commercial broth microdilution method and included the use of quality control organisms (Sensititre; Trek Diagnostic Systems Inc., Westlake, $\mathrm{OH}$ ). This method was performed in accordance with the guidelines established by the Clinical Laboratory Standards Institute (CLSI, 2008). Each of the 96 wells in the custom designed extended dilution panel for MIC determination contained serial dilutions of the following 12 antimicrobial agents as described by Apparao et al. (2009b): ampicillin (0.015-8.0 $\mu \mathrm{g} /$ $\mathrm{mL})$, ceftiofur $(0.015-4.0 \mu \mathrm{g} / \mathrm{mL})$, cephalothin $(0.03-16$ $\mu \mathrm{g} / \mathrm{mL})$, enrofloxacin $(0.03-2.0 \mu \mathrm{g} / \mathrm{mL})$, erythromycin $(0.015-4.0 \mu \mathrm{g} / \mathrm{mL})$, oxacillin $(0.12-4.0 \mu \mathrm{g} / \mathrm{mL})$, penicillin $(0.015-8.0 \mu \mathrm{g} / \mathrm{mL})$, penicillin/novobiocin $(0.06-8.0$ $\mu \mathrm{g} / \mathrm{mL})$, pirlimycin $(0.06-8.0 \mu \mathrm{g} / \mathrm{mL})$, sulfadimethoxine $(16-256 \mu \mathrm{g} / \mathrm{mL})$, spiramycin $(1.0-16 \mu \mathrm{g} / \mathrm{mL})$, and tetracycline $(0.06-8.0 \mu \mathrm{g} / \mathrm{mL})$. A positive control well was also included in each panel. In brief, isolates were grown twice on blood agar, and bacterial suspensions were prepared and standardized to a 0.5 McFarland standard per the manufacturer's instructions. Aliquots $(50 \mu \mathrm{L})$ of this suspension were dispensed into each well, and the plates were incubated aerobically at $36^{\circ} \mathrm{C}$ for 18 to $24 \mathrm{~h}$. In vitro MIC values tested were captured electronically and transferred to a database for data analysis. Quality control was performed in accordance with the guidelines specified by the CLSI (CLSI, 2008) using Staphylococcus aureus ATCC 29213 and Enterococcus fecalis ATCC 29212. All susceptibility results of quality control strains complied with the quality control ranges.

\section{Definitions and Classifications}

Resistance categories were defined based on recommendations of Schwarz et al. (2010): (1) isolates exhibiting in vitro susceptibility to all antimicrobials tested were classified as pansusceptible; (2) isolates exhibiting in vitro resistance to 1 or 2 classes of antimicrobials were classified as resistant; and (3) isolates exhibiting in vitro resistance to 3 or more classes of antimicrobials were classified as multidrug-resistant (Tenover, 2006; Schwarz et al., 2010). Antimicrobial resistance was defined as the capacity of a bacterial pathogen to survive exposure to a defined concentration (CLSI breakpoint concentration resistant) of an antimicrobial agent (CLSI, 2008). The interpretative criteria for ceftiofur, penicillin/novobiocin, and pirlimycin were based on bovine mastitis (CLSI, 2008). The interpretative criteria for ampicillin, cephalothin, erythromycin, oxacillin, penicillin, sulfadimethoxine, and tetracycline were based on human data (CLSI, 2008). The interpretative criterion for enrofloxacin was based on cattle respiratory disease (CLSI, 2008). No recommendation is currently available from the CLSI (2008) for spiramycin; therefore, the breakpoint used in Swedish Veterinary Antimicrobial Resistance Monitoring (SVARM, 2002) was considered.

Cows were classified into 2 groups: parity 1 (included isolates recovered from all first-lactation cows), or parity $>1$ (included isolates recovered from all second-andgreater-lactation cows). Case type was defined as either clinical mastitis case or subclinical mastitis case.

\section{Statistical Analysis}

Minimum inhibitory concentration test data for each antimicrobial were summarized by calculating the fiftieth $\left(\mathbf{M I C}_{\mathbf{5 0}}\right)$, and ninetieth $\left(\mathbf{M I C} \mathbf{C}_{\mathbf{9 0}}\right)$ percentiles of MIC values, as well as the proportion of isolates sus- 
Table 1. Results of microbiological examination of all quarter milk samples by case type

\begin{tabular}{|c|c|c|c|c|c|c|}
\hline \multirow[b]{3}{*}{ Result } & \multicolumn{4}{|c|}{ Case type } & & \\
\hline & \multicolumn{2}{|c|}{ Clinical } & \multicolumn{2}{|c|}{ Subclinical } & \multicolumn{2}{|c|}{ Total } \\
\hline & $\mathrm{n}$ & $\%$ & $\mathrm{n}$ & $\%$ & $\mathrm{n}$ & $\%$ \\
\hline CNS & 44 & 7.2 & 253 & 16.1 & 297 & 13.6 \\
\hline Staphylococcus aureus & 66 & 10.9 & 265 & 16.8 & 331 & 15.2 \\
\hline Streptococcus spp. & 127 & 20.9 & 67 & 4.3 & 194 & 8.9 \\
\hline Gram-negative & 158 & 26.0 & 44 & 2.8 & 202 & 9.3 \\
\hline Others $^{1}$ & 22 & 3.6 & 71 & 4.5 & 93 & 4.3 \\
\hline No growth & 168 & 27.6 & 726 & 46.1 & 894 & 40.9 \\
\hline Contaminated & 23 & 3.8 & 148 & 9.4 & 171 & 7.8 \\
\hline Total & 608 & 100.0 & 1,574 & 100 & 2,182 & 100 \\
\hline
\end{tabular}

${ }^{1}$ Corynebacterium, Arcanobacterium pyogenes, Bacillus spp., Proteus spp., and yeast.

ceptible, intermediate, or resistant and the percentage of isolates that were inhibited at each concentration of antimicrobial tested.

All statistical analyses were performed using SAS 9.2 (SAS Institute, 2008). Differences in MIC values between Staph. aureus recovered from clinical or subclinical cases of mastitis were evaluated using Proc Lifetest (SAS Institute, 2008). The concentrations of selected antimicrobials were used as time in the survival analysis. Event was defined as inhibition of bacterial growth, and isolates that were not inhibited at the greatest antimicrobial concentration were right censored.

\section{RESULTS}

\section{Results of Microbiological Analysis}

A total of 608 and 1,574 duplicate quarter milk samples were obtained from clinical and subclinical mastitis cases, respectively (Table 1$)$. More samples $(\mathrm{n}=148$; $9.4 \%$ ) obtained from subclinical cases were contaminated as compared with samples obtained from clinical cases $(\mathrm{n}=23 ; 3.8 \%)$. More samples $(\mathrm{n}=726 ; 46.1 \%)$ obtained from subclinical cases yielded no growth as compared with samples obtained from clinical cases (n $=168 ; 27.6 \%$ ). Coagulase-negative staphylococci were isolated from $44(7.2 \%)$ clinical cases and 253 (16.1\%) subclinical cases. Streptococcus spp. were isolated from $127(20.9 \%)$ clinical cases and $67(4.3 \%)$ subclinical cases. Gram-negative pathogens were isolated from 158 $(26 \%)$ clinical cases and $44(2.8 \%)$ subclinical cases. Staphylococcus aureus were isolated from 66 (10.9\%) clinical cases and $265(16.8 \%)$ subclinical cases. As a group, other pathogens (Corynebacterium, Arcanobacterium pyogenes, Bacillus spp., Proteus spp., and yeast) were isolated from $22(3.6 \%)$ clinical cases and $71(4.5 \%)$ subclinical cases (Table 1$)$.

\section{Minimum Inhibitory Concentrations of Staphylococcus aureus}

Staphylococcus aureus obtained from clinical ( $\mathrm{n}=$ 58 isolates) and subclinical ( $\mathrm{n}=58$ isolates) cases were used to determine the distribution of MIC values (Table 2). Of isolates used in the analysis, $44(38 \%)$ were obtained from first-lactation cows, $66(57 \%)$ were obtained from cows of $>1$ parity, and undefined parity $(\mathrm{n}=6 ; 5 \%$; when parity records were unavailable).

The lowest concentration of antimicrobial tested inhibited the growth of $0 \%$ (ampicillin, ceftiofur, cephalothin, and sulfadimethoxine) to $100 \%$ (penicillinnovobiocin) of isolates obtained from cases of clinical mastitis (Table 2). The lowest concentration tested inhibited the growth of $0 \%$ (sulfadimethoxine) to $94.8 \%$ (penicillin-novobiocin) of isolates obtained from subclinical cases. All isolates were inhibited by the range of concentrations tested for ceftiofur $(\mathrm{MIC} \leq 2.0)$ and oxacillin ( $\mathrm{MIC} \leq 0.5)$. The greatest concentration of erythromycin did not inhibit the growth of $6.9 \%$ of total isolates obtained from the clinical cases. The greatest concentration of enrofloxacin, sulfadimethoxine, and tetracycline did not inhibit the growth of 1.7 , 1.7 , and $10.6 \%$, respectively, of total isolates obtained from the subclinical cases. The $\mathrm{MIC}_{50}$ and $\mathrm{MIC}_{90}$ of ampicillin, ceftiofur, cephalothin, enrofloxacin, oxacillin, penicillin-novobiocin, and spiramycin were either the same or within a 1-dilution range between the $\mathrm{MIC}_{50}$ and $\mathrm{MIC}_{90}$. The greatest discrepancy of several dilutions between $\mathrm{MIC}_{50}$ and $\mathrm{MIC}_{90}$ was for penicillin, where isolates obtained from subclinical cases had an $\mathrm{MIC}_{50}$ of $0.02 \mu \mathrm{g} / \mathrm{mL}$ and $\mathrm{MIC}_{90}$ of $0.25 \mu \mathrm{g} / \mathrm{mL}$. The $\mathrm{MIC}_{50}$ of penicillin and penicillin-novobiocin was the lowest concentration tested for Staph. aureus isolates obtained from clinical and subclinical cases. The $\mathrm{MIC}_{90}$ of pirlimycin and tetracycline were less concentrated for 
Table 2. Distribution of MIC for selected Staphylococcus aureus $(\mathrm{n}=116)$ by case type

\begin{tabular}{|c|c|c|c|c|c|c|c|c|c|c|c|c|c|c|c|c|c|c|c|c|c|}
\hline \multirow[b]{2}{*}{ Antimicrobial } & \multirow[b]{2}{*}{$\begin{array}{c}\mathrm{BP}^{1} \\
(\mu \mathrm{g} / \mathrm{mL})\end{array}$} & \multirow[b]{2}{*}{ Type $^{2}$} & \multirow[b]{2}{*}{$\mathrm{n}$} & \multirow[b]{2}{*}{$\begin{array}{c}\text { Resistant } \\
(\%)\end{array}$} & \multirow[b]{2}{*}{$\mathrm{OR}^{3}$} & \multicolumn{15}{|c|}{ Percentage of isolates at each indicated MIC $(\mu \mathrm{g} / \mathrm{mL})^{4}$} & \multirow{2}{*}{$\begin{array}{l}\mathrm{NI}^{5} \\
(\%)\end{array}$} \\
\hline & & & & & & 0.015 & 0.03 & 0.06 & 0.12 & 0.25 & 0.5 & 1 & 2 & 4 & 8 & 16 & 32 & 64 & 128 & 256 & \\
\hline \multirow[t]{2}{*}{ Ampicillin } & $\leq 0.25^{6}$ & Clin & 58 & 3.4 & 1.0 & 0.0 & 10.4 & 75.9 & $\underline{8.6}$ & 1.7 & 1.7 & 1.7 & 0.0 & 0.0 & 0.0 & - & - & - & - & - & \\
\hline & & Sub & 58 & 6.9 & 2.1 & 3.4 & 19.0 & 51.7 & $\underline{17.3}$ & 1.7 & 5.2 & 0.0 & 0.0 & 1.7 & 0.0 & - & - & - & - & - & \\
\hline \multirow[t]{2}{*}{ Ceftiofur } & $\leq 2.00^{7}$ & Clin & 58 & 0.0 & & 0.0 & 0.0 & 0.0 & 1.7 & 39.7 & 39.7 & 18.9 & 0.0 & 0.0 & - & - & - & - & - & - & \\
\hline & & Sub & 58 & 0.0 & & 3.4 & 0.0 & 1.7 & 0.0 & 12.1 & 48.3 & 29.3 & 5.2 & 0.0 & - & - & - & - & - & - & \\
\hline \multirow[t]{2}{*}{ Cephalothin } & $<8.00^{6}$ & Clin & 58 & 0.0 & & - & 0.0 & 0.0 & 77.6 & 20.7 & 1.7 & 0.0 & 0.0 & 0.0 & 0.0 & 0.0 & - & - & - & - & \\
\hline & & Sub & 58 & 3.4 & & - & 1.7 & 1.7 & 53.5 & 34.6 & 1.7 & 1.7 & 1.7 & 0.0 & 0.0 & 3.4 & - & - & - & - & \\
\hline \multirow[t]{2}{*}{ Enrofloxacin } & $\leq 0.25^{8}$ & Clin & 58 & 3.4 & 1.0 & - & 3.4 & 56.9 & $\underline{32.9}$ & 3.4 & 3.4 & 0.0 & 0.0 & - & - & - & - & - & - & - & \\
\hline & & Sub & 58 & 1.7 & 0.5 & - & 1.7 & 60.4 & $\underline{34.5}$ & 1.7 & 0.0 & 0.0 & 0.0 & - & - & - & - & - & - & - & 1.7 \\
\hline \multirow[t]{2}{*}{ Erythromycin } & $\leq 0.50^{6}$ & Clin & 58 & 10.3 & & 1.7 & 1.7 & 0.0 & 48.3 & 36.3 & 1.7 & $\underline{3.4}$ & 0.0 & 0.0 & - & - & - & - & - & - & 6.9 \\
\hline & & Sub & 58 & 0.0 & & 5.2 & 1.7 & 3.4 & 70.7 & 19.0 & 0.0 & 0.0 & 0.0 & 0.0 & - & - & - & - & - & - & \\
\hline \multirow[t]{2}{*}{ Oxacillin } & $\leq 2.00^{6}$ & Clin & 58 & 0.0 & & - & - & - & 41.4 & $\underline{55.2}$ & 3.4 & 0.0 & 0.0 & 0.0 & - & - & - & - & - & - & \\
\hline & & Sub & 58 & 0.0 & & - & - & - & 48.3 & 46.5 & 5.2 & 0.0 & 0.0 & 0.0 & - & - & - & - & - & - & \\
\hline \multirow{2}{*}{ Penicillin } & $\leq 0.12^{6}$ & Clin & 58 & 3.4 & 1.0 & 91.5 & 3.4 & 1.7 & 0.0 & 0.0 & 0.0 & 3.4 & 0.0 & 0.0 & 0.0 & - & - & - & - & - & \\
\hline & & Sub & 58 & 10.3 & 3.1 & $\overline{75.9}$ & 10.4 & 0.0 & 3.4 & $\underline{3.4}$ & 5.2 & 0.0 & 0.0 & 1.7 & 0.0 & - & - & - & - & - & \\
\hline \multirow[t]{2}{*}{ Penicillin-novobiocin } & $\leq 2.00^{7}$ & Clin & 57 & 0.0 & & - & - & 100.0 & 0.0 & 0.0 & 0.0 & 0.0 & 0.0 & 0.0 & 0.0 & - & - & - & - & - & \\
\hline & & Sub & 58 & 3.4 & & - & - & 94.9 & 1.7 & 0.0 & 0.0 & 0.0 & 0.0 & 0.0 & 3.4 & - & - & - & - & - & \\
\hline \multirow{2}{*}{ Pirlimycin } & $\leq 2.00^{7}$ & Clin & 57 & 5.2 & 1.0 & - & - & $\frac{7.00}{8.8}$ & 33.4 & 21.1 & 5.3 & 15.8 & 10.5 & 1.7 & 3.4 & - & - & - & - & - & \\
\hline & & Sub & 58 & 3.4 & 10.7 & - & - & 5.2 & 29.3 & 48.3 & 10.4 & 1.7 & 1.7 & 3.4 & 0.0 & - & - & - & - & - & \\
\hline \multirow{2}{*}{ Spiramycin } & $\leq 32.00^{9}$ & Clin & 58 & & NI & - & - & - & - & - & - & 38.0 & 53.5 & 6.8 & 0.0 & 1.7 & - & - & - & - & \\
\hline & & Sub & 58 & & NI & - & - & - & - & - & - & 43.1 & $\underline{53.5}$ & 3.4 & 0.0 & 0.0 & - & - & - & - & \\
\hline \multirow[t]{2}{*}{ Sulfadimethoxine } & $\leq 256.0^{6}$ & Clin & 58 & 0.0 & & - & - & - & - & - & - & - & - & 0.0 & 0.0 & 56.9 & 3.4 & 27.6 & 12.1 & 0.0 & \\
\hline & & Sub & 58 & 1.7 & & - & - & - & - & - & - & - & - & 0.0 & 0.0 & 53.5 & 32.8 & $\underline{8.6}$ & 3.4 & 0.0 & 1.7 \\
\hline \multirow[t]{2}{*}{ Tetracycline } & $\leq 4.00^{6}$ & Clin & 55 & 6.9 & 1.0 & - & - & 1.8 & 14.6 & 58.2 & 20.0 & $\underline{1.8}$ & 0.0 & 1.8 & 1.8 & - & - & $\overline{-}$ & - & - & \\
\hline & & Sub & 58 & 12.3 & 1.8 & - & - & 8.8 & 36.9 & 38.6 & 1.7 & 1.7 & 0.0 & 0.0 & 1.7 & - & - & - & - & - & 10.6 \\
\hline
\end{tabular}

${ }^{1} \mathrm{BP}=$ breakpoint [the MIC at which an isolate is considered susceptible according to the Clinical Laboratory Standards Institute (CLSI) guidelines; CLSI, 2008].

${ }^{2} \mathrm{Clin}=$ isolates obtained from clinical cases; $\mathrm{Sub}=$ isolates obtained from subclinical cases.

${ }^{3} \mathrm{OR}=$ odds ratio (odds that isolates obtained from a subclinical sample were resistant as compared with isolates obtained from clinical cases).

@ Dashes indicate values not tested for the indicated antimicrobial. The 50th-percentile MIC $\left(\mathrm{MIC}_{50}\right)$ value is in bold; the 90 th-percentile $\mathrm{MIC}$ (MIC ${ }_{90}$ ) value is underlined. A bold 을 and underlined value is both the $\mathrm{MIC}_{50}$ and $\mathrm{MIC}_{90}$.

${ }^{5} \mathrm{NI}=$ isolates that were not inhibited at the highest concentration of the antimicrobial tested.

卷. $\quad{ }^{6}$ Interpretive criteria based on human data.

D) $\quad{ }^{7}$ Interpretive criteria based on bovine mastitis.

${ }^{8}$ Interpretive criteria based on bovine respiratory disease.

Interpretive criteria based on European standards (SVARM, 2002). 
Table 3. Patterns of resistance in Staphylococcus aureus $(\mathrm{n}=12)$ obtained from cases of bovine mastitis exhibiting resistance for more than 1 antimicrobial

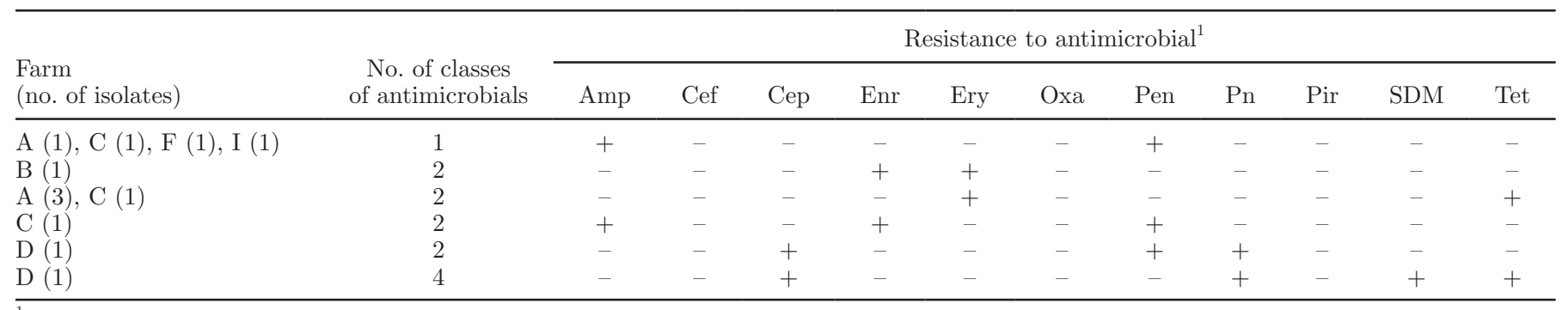

${ }^{1} \mathrm{Amp}=$ ampicillin; Cef = ceftiofur; Cep = cephalothin; Enr = enrofloxacin; Ery = erythromycin; Oxa = oxacillin; Pen = penicillin; Pn $=$ penicillin-novobiocin; Pir = pirlimycin; $\mathrm{SDM}=$ sulfadimethoxine; Tet $=$ tetracycline .

Staph. aureus isolates obtained from subclinical cases than the $\mathrm{MIC}_{90}$ for isolates obtained from clinical cases (Table 2).

Survival curves of Staph. aureus relative to MIC demonstrated heterogeneity among case types (clinical and subclinical) for ceftiofur (log-rank <0.01), cephalothin (log-rank <0.01), and erythromycin $(\log -$ rank $<0.01)$ (curves not shown). For ceftiofur, cephalothin, and erythromycin, a greater proportion of isolates obtained from subclinical cases was inhibited at same concentration compared with isolates obtained from clinical cases. Homogeneous survival curves for ampicillin, enrofloxacin, penicillin, and tetracycline (log-rank $>0.07$; Wilcoxon >0.08) among case type were observed for all isolates studied. No Staph. aureus isolates were censored for oxacillin, penicillin/novobiocin, pirlimycin, sulfadimethoxine, or spiramycin.

\section{Resistance of Staphylococcus aureus}

Of Staph. aureus isolates $(\mathrm{n}=116), 87(75 \%)$ were pansusceptible, $28(24.1 \%)$ exhibited resistance to 1 (n $=21)$ or $2(\mathrm{n}=7)$ classes of antimicrobials, and 1 $(0.9 \%)$ exhibited multidrug resistance. Resistance was detected in $12(10.3 \%)$ isolates for tetracycline, $8(7.0 \%)$ isolates for penicillin, 6 (5.2\%) isolates for ampicillin, $6(5.2 \%)$ isolates for erythromycin, $5(4.3 \%)$ isolates for pirlimycin, $3(2.6 \%)$ isolates for enrofloxacin, 2 $(1.7 \%)$ isolates for cephalothin, $2(1.7 \%)$ isolates for penicillin-novobiocin, and $1(0.9 \%)$ isolate for sulfadimethoxine. No isolates obtained from any clinical cases were observed with resistance to ceftiofur, cephalothin, oxacillin, penicillin-novobiocin, or sulfadimethoxine. No isolates obtained from subclinical cases were observed with resistance to ceftiofur, erythromycin, or oxacillin. Isolates exhibiting resistance to 1 or 2 classes of antimicrobials were from 8 farms. Of isolates with resistance to more than 1 antimicrobial but only 2 classes of antimicrobials $(\mathrm{n}=11), 5$ patterns were observed (Table 3). Of those isolates, 4 exhibited resistance to penicillin and ampicillin ( $\beta$-lactams), and 4 exhibited resistance to enrofloxacin (fluoroquinolone) and erythromycin (macrolide; Table 3). Multidrug resistance was observed in Staph. aureus obtained from a subclinical case. This isolate demonstrated resistance to 4 antimicrobials (cephalothin, penicillin, sulfadimethoxine, and tetracycline; Table 3). No isolate exhibited resistance to more than 4 antimicrobials. For ampicillin, penicillin, pirlimycin, and tetracycline, isolates obtained from subclinical cases were more likely to be resistant than isolates obtained from clinical cases (Table 2).

\section{DISCUSSION}

Herds enrolled in this study were not selected to be representative of Wisconsin dairy herds but were recruited because the herd history suggested that Staph. aureus would be recovered from cases of clinical and subclinical mastitis. As expected, a greater prevalence of Staph. aureus was recovered from milk samples as compared with previous studies conducted in Wisconsin (Makovec and Ruegg, 2003a; Pol and Ruegg, 2007). Furthermore, this study showed that Staph. aureus is still a problem in some dairy herds in Wisconsin. In these herds, Staph. aureus accounted for 17\% $(\mathrm{n}=265)$ of isolates from subclinical mastitis cases.

Previous studies examining antimicrobial susceptibility of Staph. aureus isolated from bovine mastitis have used either the disk diffusion method (Watts and Salmon, 1997; Aarestrup and Jensen, 1998), which is a qualitative method, or broth microdilution test (quantitative method) using commercially available test panels that have a fixed and standardized range of antimicrobial concentrations. On these panels, isolates frequently are inhibited at the lowest or greatest concentrations, showing that other dilutions should be included. In the present study, broth microdilution test was used for determination of antimicrobial susceptibility; however, we used a custom-designed panel with a greater number of antimicrobials and broader range of dilutions developed 
by Apparao et al. (2009b). Comparison of results of antimicrobial susceptibility testing among studies is difficult because of differences in methodology. Moreover, based on CLSI (2008), only a few antimicrobials have a valid veterinary breakpoint for bovine mastitis (ceftiofur, penicillin/novobiocin, and pirlimycin). The lack of interpretative criteria specific to most mastitis therapeutics (Watts et al., 1994) complicates comparisons among studies.

Considering these points, minimum inhibitory concentrations of pathogens isolated in this study were generally low and comparable to MIC values reported previously for Staph. aureus (De Oliveira et al., 2000; Pol and Ruegg, 2007). For example, for cephalothin, almost all MIC values (with the exception of 2 isolates obtained from subclinical cases) were less than the breakpoint. Resistance to cephalothin was almost nonexistent, as reported previously (De Oliveira et al. 2000; Pol and Ruegg, 2007). However, Gentilini et al. (2000) determined in vitro susceptibility of Staph. aureus $(\mathrm{n}=206)$ using the E-test and reported greater $\mathrm{MIC}_{90}$ for penicillin, oxacillin, and cephalothin as compared with the results observed in this study. These differences may have been observed due to differences in the methodologies or regional differences in Staph. aureus populations.

Other studies using isolates from clinical and subclinical cases (Gentilini et al., 2000; Makovec and Ruegg, 2003b) did not compare MIC distribution based on the presentation of mastitis. In the present study, inhibitory concentration of ceftiofur, cephalothin, and erythromycin varied between clinical and subclinical cases and the distribution of MIC values, rather than occurrence of resistance, may be more useful for monitoring changes relative to antimicrobial exposure.

In agreement with previous research (Sabour et al., 2004; Apparao et al., 2009a), 75\% of Staph. aureus were susceptible to all antimicrobials tested and no resistance to oxacillin was observed. Oxacillin is one method that is used to detect methicillin resistance in staphylococci, and in the United States, methicillin-resistant Staph. aureus are rarely reported to be isolated in milk samples obtained from dairy cattle (Werckenthin et al., 2001; Guérin-Faublée et al., 2003; Virgin et al., 2009). Similar to previous research (Gentilini et al., 2000; Pitkälä et al., 2004), no isolates obtained from subclinical mastitis cases were resistant to cephalothin even though this compound is one of the most frequently used intramammary treatments (Pol and Ruegg, 2007). Similar to previous reports, resistance of Staph. aureus to penicillin was the most commonly observed resistance phenotype (Myllys et al., 1998; Rabello et al., 2005). Changes in prevalence of penicillin-resistance with time have been identified in some countries, and differences among countries have been reported. In the United States, Makovec and Ruegg (2003b) reported a decrease of resistance to penicillin (from 49 to 30\%) in isolates obtained from milk samples submitted to a state diagnostic laboratory between 1994 and 2001. Younis et al. (2000) investigated 400 Staph. aureus isolates from chronic subclinical cases from Israeli dairy herds $(\mathrm{n}=15)$ and identified a large proportion of resistance to penicillin (96.6\%). In the current study, $13.7 \%$ of isolates were resistant to penicillin and the majority of resistant organisms were obtained from subclinical cases. Greater resistance to tetracycline was observed in this study as compared with previous reports. Nineteen percent of isolates were resistant to tetracycline. Makovec and Ruegg (2003b) reported that resistance to tetracycline increased from 18 to $25 \%$ of isolates between 1994 and 2001. Tetracycline resistance was reported less frequently by Sabour et al. (2004; $\mathrm{n}=3 ; 1.4 \%$ ) and Hendriksen et al. (2008; 2 to $6 \%$, depending on the origin of the isolate: England, France, Italy, Latvia, Portugal, Denmark, the Netherlands, Norway, Sweden, Switzerland, Spain, Finland, or Belgium). Among all isolates, about $10 \%$ were resistant to 2 or more antimicrobials but only 1 isolate exhibited multidrug resistance. Two patterns contributed to the majority of resistance to more than 1 antimicrobial, 4 isolates were resistant to ampicillin and penicillin, and another 4 were resistant to erythromycin and tetracycline. Comparing multidrug resistance among studies is difficult due the lack of a universally accepted definition of multidrug resistance (Schwarz et al., 2010). Resistance to different antimicrobials from the same antimicrobial class is most likely mediated by the same mechanism and so should not be considered multidrug resistance. Future research should be directed toward identifying the presence of antimicrobial resistance genes present in mastitis pathogens.

\section{CONCLUSIONS}

Overall, antimicrobial resistance to ampicillin, enrofloxacin, erythromycin, penicillin, pirlimycin, and tetracycline was found in some Staph. aureus recovered from subclinical and clinical mastitis cases. In addition, multidrug resistance was identified in only 1 isolate. The use of extended dilution ranges of MIC values to follow possible changes in the resistance pattern and possible emergence of resistance should be encouraged.

\section{ACKNOWLEDGMENTS}

The authors thank the farmers and the National Council for Scientific and Technological Development (CNPq-Brazil, Brasília) for funding H. Langoni. 


\section{REFERENCES}

Aarestrup, F. M., and N. E. Jensen. 1998. Development of penicillin resistance among Staphylococcus aureus isolated from bovine mastitis in Denmark and other countries. Microb. Drug Resist. $4: 247-256$.

Apparao, D., L. Oliveira, and P. L. Ruegg. 2009a. Relationship between results of in vitro susceptibility tests and outcomes following treatment with pirlimycin hydrochloride in cows with subclinical mastitis associated with gram-positive pathogens. J. Am. Vet. Med. Assoc. 234:1437-1446.

Apparao, M. D., P. L. Ruegg, A. Lago, S. Godden, R. Bey, and K. Leslie. 2009b. Relationship between in vitro susceptibility test results and treatment outcomes for gram-positive mastitis pathogens following treatment with cephapirin sodium. J. Dairy Sci. $92: 2589-2597$

Barbosa, T. M., and S. B. Levy. 2000. The impact of antibiotic use on resistance development and persistence. Drug Resist. Updat. $3: 303-311$.

Burgos, J. M., B. A. Ellington, and M. F. Varela. 2005. Presence of multidrug-resistant enteric bacteria in dairy farm topsoil. J. Dairy Sci. 88:1391-1398

CLSI (Clinical Laboratory Standards Institute). 2008. Performance standards for antimicrobial disk and dilution susceptibility tests for bacteria isolated from animals; Approved standard-3rd ed. Vol. 28, No. 8. Clinical Laboratory Standards Institute, Wayne, PA.

De Oliveira, A. P., J. L. Watts, S. A. Salmon, and F. M. Aarestrup. 2000. Antimicrobial susceptibility of Staphylococcus aureus isolated from bovine mastitis in Europe and the United States. J. Dairy Sci. 83:855-862.

Enright, M. C., D. A. Robinson, G. Randle, E. J. Feil, H. Grundmann, and B. G. Spratt. 2002. The evolutionary history of methicillinresistant Staphylococcus aureus (MRSA). Proc. Natl. Acad. Sci. USA 99:7687-7692.

Gentilini, E., G. Denamiel, P. Llorente, S. Godaly, M. Rebuelto, and O. DeGregorio. 2000. Antimicrobial susceptibility of Staphylococcus aureus isolated from bovine mastitis in Argentina. J. Dairy Sci. $83: 1224-1227$.

Guérin-Faublée, V., G. Carret, and P. Houffschmitt. 2003. In vitro activity of 10 antimicrobial agents against bacteria isolated from cows with clinical mastitis. Vet. Rec. 152:466-471.

Guillemot, D. 1999. Antibiotic use in human and bacterial resistance. Curr. Opin. Microbiol. 2:494-498.

Hendriksen, R. S., D. J. Mevius, A. Schroeter, C. Teale, D. Meunier, P. Butaye, A. Franco, A. Utinane, A. Amado, M. Moreno, C. Greko, K. Stärk, C. Berghold, A.-L. Myllyniemi, D. Wasyl, M. Sunde, and F. M. Aarestrup. 2008. Prevalence of antimicrobial resistance among bacterial pathogens from cattle in different European countries: 2002-2004. Acta Vet. Scand. 50:28-37.

Hoe, F. G. H., and P. L. Ruegg. 2005. Relationship between antimicrobial susceptibility of clinical mastitis pathogens and treatment outcome in cows. J. Am. Vet. Med. Assoc. 227:1461-1468.

Levy, S. B. 1992. The individual and antibiotic resistance. Pages 205222 in The Antibiotic Paradox: How Miracle Drugs are Destroying the Miracle. Plenum Press, New York, NY.

Makovec, J. A., and P. L. Ruegg. 2003a. Results of milk samples submitted for microbiological examination in Wisconsin from 1994 to 2001. J. Dairy Sci. 86:3466-3472.

Makovec, J. A., and P. L. Ruegg. 2003b. Antimicrobial resistance of bacteria isolated from dairy cow milk samples submitted for bacterial culture: 8,905 samples (1994-2001). J. Am. Vet. Med. Assoc. $222: 1582-1589$.

Myllys, V., K. Asplund, E. Brofeldt, V. Hirvelä-Koski, T. HonkanenBuzalski, J. Junttila, L. Kulkas, O. Myllykangas, M. Niskanen, H.
Saloniemi, M. Sandholm, and T. Saranpää. 1998. Bovine mastitis in Finland in 1988 and 1995-Changes in prevalence and antimicrobial resistance. Acta Vet. Scand. 39:119-126.

NMC (National Mastitis Council). 1999. Laboratory Handbook on Bovine Mastitis. National Mastitis Council, Madison. WI.

Neu, H. C. 1992. The crisis in antibiotic resistance. Science 257:10641073

Pitkälä, A., M. Haveri, S. Pyörälä, V. Myllys, and T. Honkanen-Buzalski. 2004. Bovine mastitis in Finland 2001-Prevalence, distribution of bacteria, and antimicrobial resistance. J. Dairy Sci. $87: 2433-2441$

Pol, M., and P. L. Ruegg. 2007. Relationship between antimicrobial drug usage and antimicrobial susceptibility of gram-positive mastitis pathogens. J. Dairy Sci. 90:262-273.

Rabello, R. F., C. R. Souza, R. S. Duarte, R. M. Lopes, L. M. Teixeira, and A. C. Castro. 2005. Characterization of Staphylococcus aureus isolates recovered from bovine mastitis in Rio de Janeiro, Brazil. J. Dairy Sci. 88:3211-3219.

Sabour, P. M., J. J. Gill, D. Lepp, J. C. Pacan, R. Ahmed, R. Dingwell, and K. Leslie. 2004. Molecular typing and distribution of Staphylococcus aureus isolates in eastern Canadian dairy herds. J. Clin. Microbiol. 42:3449-3455.

SAS Institute. 2008. SAS/STAT User's Guide. Version 9.2. SAS Inst. Inc., Cary, NC.

Schwarz, S., P. Silley, S. Simjee, N. Woodford, E. van Duijkeren, A. P. Johnson, and W. Gaastra. 2010. Assessing the antimicrobial susceptibility of bacteria obtained from animals. Vet. Microbiol. 141:1-4.

SVARM. 2002. Swedish Veterinary Antimicrobial Resistance Monitoring. The Natl. Vet. Inst. (SVA), Uppsala, Sweden.

Tenover, F. C. 2006. Mechanisms of antimicrobial resistance in bacteria. Am. J. Med. 119:S3-S10.

Virgin, J. E., T. M. van Slyke, J. E. Lombard, and R. N. Zadoks. 2009 Methicillin resistant Staphylococcus aureus detection in US bulk tank milk. J. Dairy Sci. 92:4988-4991.

Watts, J. L., and S. A. Salmon. 1997. Activity of selected antimicrobial agents against strains of Staphylococcus aureus isolated from bovine intramammary infections that produce $\beta$-lactamase. J. Dairy Sci. 80:788-791.

Watts, J. L., R. J. Yancey, J. R. Sarah, S. A. Salmon, and C. A. Case. 1994. A 4-year survey of antimicrobial susceptibility trends for isolates from cattle with bovine respiratory disease in North America. J. Clin. Microbiol. 32:725-731

Werckenthin, C., M. Cardoso, J.-L. Martel, and S. Schwarz. 2001 Antimicrobial resistance in staphylococci from animals with particular reference to bovine Staphylococcus aureus, porcine Staphylococcus hyicus, and canine Staphylococcus intermedius. Vet. Res. $32: 341-362$.

Wilson, D. J., R. N. Gonzalez, and H. H. Das. 1997. Bovine mastitis pathogens in New York and Pennsylvania: Prevalence and effects on somatic cell count and milk production. J. Dairy Sci $80: 2592-2598$

Younis, A., G. Leitner, D. E. Heller, Z. Samra, R. Gadba, G. Lubashevsky, M. Chaffer, N. Yadlin, M. Winkler, and A. Saran. 2000. Phenotypic characteristics of Staphylococcus aureus isolated from bovine mastitis in Israeli dairy herds. J. Vet. Med. B Infect. Dis. Vet. Public Health 47:591-597.

Zadoks, R., W. van Leeuwen, H. Barkema, O. Sampimon, H. Verbrugh, Y. H. Schukken, and A. van Belkum. 2000. Application of pulsed-field gel electrophoresis and binary typing as tools in veterinary clinical microbiology and molecular epidemiologic analysis of bovine and human Staphylococcus aureus isolates. J. Clin. Microbiol. 38:1931-1939. 